\title{
Endoscopic transorbital route to the cavernous sinus through the meningo-orbital band: a descriptive anatomical study
}

\author{
lacopo Dallan, MD, ${ }^{1}$ Alberto Di Somma, MD, ${ }^{2}$ Alberto Prats-Galino, MD, PhD, ${ }^{3}$ \\ Domenico Solari, MD, PhD, ${ }^{2}$ Isam Alobid, MD, ${ }^{4}$ Mario Turri-Zanoni, MD, ${ }^{5}$ Giacomo Fiacchini, MD, ${ }^{1}$ \\ Paolo Castelnuovo, MD, ${ }^{5}$ Giuseppe Catapano, MD, ${ }^{6}$ and Matteo de Notaris, MD, PhD ${ }^{6}$
}

\begin{abstract}
${ }^{1}$ First Otorhinolaryngologic Unit, Azienda Ospedaliero-Universitaria Pisana, Pisa; ${ }^{2}$ Division of Neurosurgery, Department of Neurosciences, Reproductive and Odontostomatological Sciences, Università degli Studi di Napoli Federico II, Naples; ${ }^{5}$ Unit of Otorhinolaryngology, Department of Biotechnology and Life Sciences, University of Insubria, Varese; ${ }^{6}$ Department of Neuroscience, G. Rummo Hospital, Neurosurgery Operative Unit, Benevento, Italy; ${ }^{3}$ Laboratory of Surgical Neuroanatomy (LSNA), Faculty of Medicine, Universitat de Barcelona; and ${ }^{4}$ Rhinology and Skull Base Unit, Department of Otorhinolaryngology, Hospital Clínic de Barcelona, Universitat de Barcelona, Spain
\end{abstract}

OBJECTIVE Exposure of the cavernous sinus is technically challenging. The most common surgical approaches use well-known variations of the standard frontotemporal craniotomy. In this paper the authors describe a novel ventral route that enters the lateral wall of the cavernous sinus through an interdural corridor that includes the removal of the greater sphenoid wing via a purely endoscopic transorbital pathway.

METHODS Five human cadaveric heads (10 sides) were dissected at the Laboratory of Surgical NeuroAnatomy of the University of Barcelona. To expose the lateral wall of the cavernous sinus, a superior eyelid endoscopic transorbital approach was performed and the anterior portion of the greater sphenoid wing was removed. The meningo-orbital band was exposed as the key starting point for revealing the cavernous sinus and its contents in a minimally invasive interdural fashion.

RESULTS This endoscopic transorbital approach, with partial removal of the greater sphenoid wing followed by a "natural" ventral interdural dissection of the meningo-orbital band, allowed exposure of the entire lateral wall of the cavernous sinus up to the plexiform portion of the trigeminal root and the petrous bone posteriorly and the foramen spinosum, with the middle meningeal artery, laterally.

CONCLUSIONS The purely endoscopic transorbital approach through the meningo-orbital band provides a direct view of the cavernous sinus through a simple and rapid means of access. Indeed, this interdural pathway lies in the same sagittal plane as the lateral wall of the cavernous sinus. Advantages include a favorable angle of attack, minimal brain retraction, and the possibility for dissection through the interdural space without entering the neurovascular compartment of the cavernous sinus. Surgical series are needed to demonstrate any clinical advantages and disadvantages of this novel route.

https://thejns.org/doi/abs/10.3171/2016.8.JNS16465

KEY WORDS cavernous sinus; endoscopic transorbital; superior eyelid transorbital; meningo-orbital band; anatomy

【 ESIONS in the cavernous sinus were long considered inoperable because of the risk of bleeding from the venous plexus or injury to important neurovascular structures such as the internal carotid artery and the cranial and sympathetic nerves. Even in experienced hands, surgery in this region is associated with significant morbidity. ${ }^{1,9,37}$
Pioneering surgeons such as Parkinson, ${ }^{38-41}$ Dolenc, ${ }^{15-18}$ and Hakuba ${ }^{25-28,35,36}$ have paved the way for a greater multidimensional understanding of the anatomy of the cavernous sinus, with the result that this previously inaccessible region is no longer a "no-man's land." Using Dolenc's technique, tumors in this location can be resected safely without entering the cavernous sinus neurovascular

ABBREVIATIONS $\mathrm{MOB}=$ meningo-orbital band; $\mathrm{SOF}=$ superior orbital fissure. 
compartment, ${ }^{17}$ and over the past 2 decades several studies have described numerous approaches with acceptable morbidity and mortality. $2,3,20,22,26,27,30,42,43$ Nevertheless, controversy relating to the optimal route for different kinds of cavernous sinus lesions persists, and the cavernous sinus remains one of the most challenging and unfamiliar sites for many neurosurgeons and skull base surgeons. As a consequence, new routes are still needed to unlock this deep region more safely.

Over the years, transnasal corridors have been extensively described in both anatomical and clinical studies. ${ }^{4,5,8,13,14,21}$ However, lesions arising in or extending to the lateral wall of the cavernous sinus remain out of range for such approaches. On the other hand, data from the literature shows that trans- and supra-orbital approaches have allowed management of the anterior and middle skull base with a superolateral trajectory. ${ }^{7,32,33}$ The idea of using the lateral orbital wall as a corridor for entry to deeper brain areas is not new, and in recent years the superior eyelid transorbital approach, with endoscopic assistance, has been proposed as a way to access, in a minimally invasive fashion, the anterior and middle cranial fossa. ${ }^{6,31}$

From a technical viewpoint, this kind of transorbital route does not require the removal of the orbital rim or frontal bone and offers easy access to the anterior portion of the greater sphenoid wing covering the temporal pole. From this perspective, the endoscopic transorbital route provides straight, ventral access to the most superficial dural band tethering the frontotemporal basal dura to the periorbita-the so-called meningo-orbital band (MOB) ${ }^{24,29}$ The MOB is a sagittally oriented structure between the temporobasal dura and the lateral aspect of the periorbita. It is typically exposed transcranially via a frontotemporal craniotomy along the lateral border of the superior orbital fissure (SOF) when the temporal basal dura is fully retracted. From an anatomical viewpoint the MOB has been described as leading directly to the interdural space of the cavernous sinus..$^{22,23}$

Taking such data into account, we hypothesized that if the meningo-orbital band is sharply dissected via an endoscopic superior eyelid transorbital approach, it might allow us to expose the lateral wall of the cavernous sinus in a minimally invasive interdural fashion with very limited brain retraction or cranial nerve manipulation and with a favorable attack angle. Accordingly, in the present study, we describe just such a surgical route to the cavernous sinus that involves the removal of the greater sphenoid wing via an endoscopic transorbital pathway.

\section{Methods}

Anatomical dissections were performed at the Laboratory of Surgical Neuroanatomy in the Human Anatomy and Embryology Unit of the University of Barcelona Faculty of Medicine. The ethics committee of the University of Barcelona approved this study.

Surgical photographs were obtained in selected cases in which patients were treated by means of the transorbital endoscopic approach in 2 Italian tertiary care referral institutions (University of Pisa and University of Varese). The superior eyelid transorbital approach was performed using a rigid endoscope $4 \mathrm{~mm}$ in diameter and $18 \mathrm{~cm}$ in length and with $0^{\circ}$ and $30^{\circ}$ optic lenses (Karl Storz). The endoscope was connected to a light source through a fiberoptic cable and to a high-definition (HD) camera (Endovision Telecam SL, Karl Storz). The microanatomical part of the dissections was performed at optical magnification ranging from 3 to 40 (OPM, Zeiss).

Anatomical dissections were performed in 5 cadaver heads (10 sides). The common carotid arteries were isolated, cannulated, and injected with red latex. Veins were perfused in selected specimens using blue latex.

In accordance with previously published papers ${ }^{10,12}$ the incision was made through the skin and the orbicularis muscle and a skin-muscle flap was raised, mostly superolaterally, until the bony orbital rim was identified. The periosteum was then cut and a subperiosteal/subperiorbital plane was found (Fig. 1). Dissection proceeded using this plane until the superior and inferior orbital fissures were reached, to adequately expose the anterior portion of the greater wing of the sphenoid.

A malleable retractor was used to protect the periorbita, displacing the orbital content inferomedially and creating room for further dissection. Next, a $0^{\circ}$ and/or $30^{\circ}$ endoscope (Karl Storz) was introduced to monitor the subsequent steps. The SOF was then protected, and drilling of the greater sphenoid wing allowed us to clearly identify the MOB (Fig. 2).

\section{Results}

\section{Transorbital Interdural Pathway-Anatomical Observations}

In all specimens, once the orbital rim was skeletonized, a careful subperiosteal/periorbital dissection was performed until the SOF was identified (Video 1).

VIDEO 1. Video clip showing anatomical demonstration of the endoscopic superior eyelid transorbital approach to the lateral wall of the cavernous sinus. $\mathrm{ACF}=$ anterior cranial fossa; $\mathrm{dMCF}=$ dura propria of the middle cranial fossa; $G G$ = gasserian ganglion; III = third cranial nerve; IOF = inferior orbital fissure; IV = fourth cranial nerve; $\mathrm{MCF}=$ middle cranial fossa; $\mathrm{MMA}=$ middle meningeal artery; $\mathrm{OC}$ = optic canal; OR = orbital rim; RMA = recurrent meningeal artery; SOF = superior orbital fissure; TM = temporalis muscle; IwCS, lateral wall of the cavernous sinus; V1 = ophthalmic branch of the trigeminal nerve; V2 = maxillary branch of the trigeminal nerve; V3 $=$ mandibular branch of the trigeminal nerve. Copyright Alberto Di Somma. Published with permission. Click here to view.

Several bridging vessels were seen and cut during dissection. ${ }^{6}$ Not infrequently, small, generally nameless, foramina were identified lateral to the SOF. The closest and largest of these is known as the cranio-orbital foramen or Hirtl's foramen. ${ }^{19}$ The recurrent meningeal artery or meningolacrimal branch may pass through this foramen, which is present in 50\%-60\% of cases.

The greater wing of the sphenoid was then removed until the dura mater covering the temporal pole came into view. In some cases, the bone covering the basal frontal lobe was also removed to obtain better exposure of the SOF.

Accordingly, the MOB leading to the lateral wall of the cavernous sinus could be seen in the center of the surgical field (Fig. 2). Anatomically, the lateral wall of the cavernous sinus is composed of 2 dural layers; the outer layer 

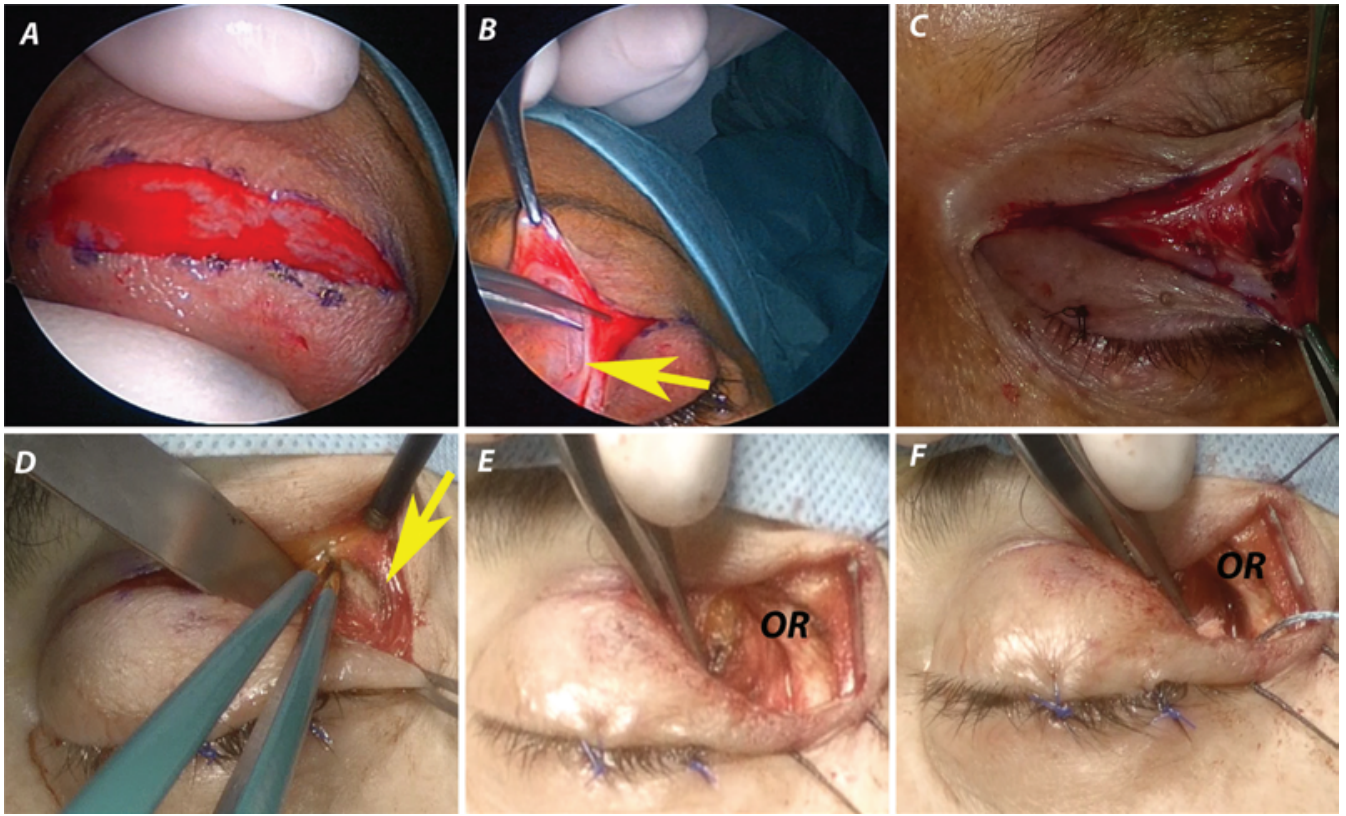

FIG. 1. Intraoperative photographs showing the superior eyelid transorbital approach, left orbit. The incision is made through the skin $(\mathbf{A})$ and the orbicularis muscle (B and C); the skin-muscle flap is raised mostly superolaterally. A malleable retractor is used to mobilize the orbital content inferomedially (D). The periosteum is cut and a subperiosteal/subperiorbital plane is followed ( $E$ and F). The yellow arrows indicate the orbicularis oculi muscle. OR = orbital rim. Figure is available in color online only.

(meningeal dura or dura propria), and the inner one (true cavernous membrane). This last layer is made up of the epineurium of cranial nerves and surrounding connective tissue, and a cleavage plane between the inner and outer dural layers can be easily identified. ${ }^{45}$

Strictly speaking, the MOB is not a true anatomical structure. It is described as the most superficial duralperiosteal band that tethers the frontotemporal basal dura to the periorbita. Anatomically speaking, along the lateral margin of the SOF the periosteal layer of the dura mater is contiguous with the periosteal layer of the periorbita. ${ }^{23}$ So, in fact, the MOB can be identified as a periosteal fold/ bridge stretching between the periorbita and the temporal lobe dura. As highlighted by Froelich et al., ${ }^{23}$ the width of this fold varies according to the shape of the lateral end of the narrow part of the SOF.

Running through the MOB are several nameless dural vessels and sometimes also the recurrent meningeal artery. There is usually a space between the dura propria and the epineurium of the cranial nerves where the nerves exit the intradural space. This space is more evident in the case of the mandibular nerve and trigeminal ganglion but it can be identified in other areas as well.

At the level of the lateral wall of the cavernous sinus, the true cavernous membrane continues intraorbitally as the epineurium of the cranial nerves. So, removing the greater wing of the sphenoid close to the lateral aspect of the $\mathrm{SOF}$, allows the periorbita-periosteal dura transition (corresponding to the $\mathrm{MOB}$ ) to float off the underlying dura propria and true cavernous membrane. Therefore a sharp and gentle dissection of this bridge, and in particular of the meningo-orbital band, "naturally" reveals the lateral wall of the cavernous sinus via an interdural pathway (Fig. 3).

Surgically speaking, this space is very important be- cause it offers access to the inner layer of the lateral wall without the need to enter the venous compartment of the sinus itself, and, even more importantly, it provides access without manipulation of the cavernous sinus' cranial nerves. This virtually bloodless surgical plane has been reported in the clinical setting by Fukuda et al. ${ }^{24}$

Additionally, MOB release permits the gentle and partial displacement (extradurally) of the medial part of the temporal lobe.

In the subsequent steps of the dissection, the meningeal dura was peeled off in a posterolateral direction, thus progressively exposing the nerves enclosed in the true cavernous membrane. The identification of V1 and V2 usually preceded identification of the third and fourth cranial nerves. This interdural corridor provided an easy and straight visualization of the first 2 branches of the trigeminal nerve (Fig. 4). As the dissection proceeded posteriorly, the trochlear and oculomotor nerves came into view, just superior to the ophthalmic branch of the trigeminal nerve (Fig. 5).

At the end of the interdural dissection, a complete visualization of the lateral wall of the cavernous sinus could be obtained, including oculomotor and trochlear nerves, the first 2 branches of the trigeminal nerve up to the gasserian ganglion and the distal/plexiform portion of the trigeminal root posteriorly and the mandibular branch of the trigeminal nerve and the middle meningeal artery laterally (Fig. 6).

\section{Discussion}

The traditional belief that lesions arising in or extending to the cavernous sinus are inoperable has been abandoned over the years. Innovative surgical techniques have 

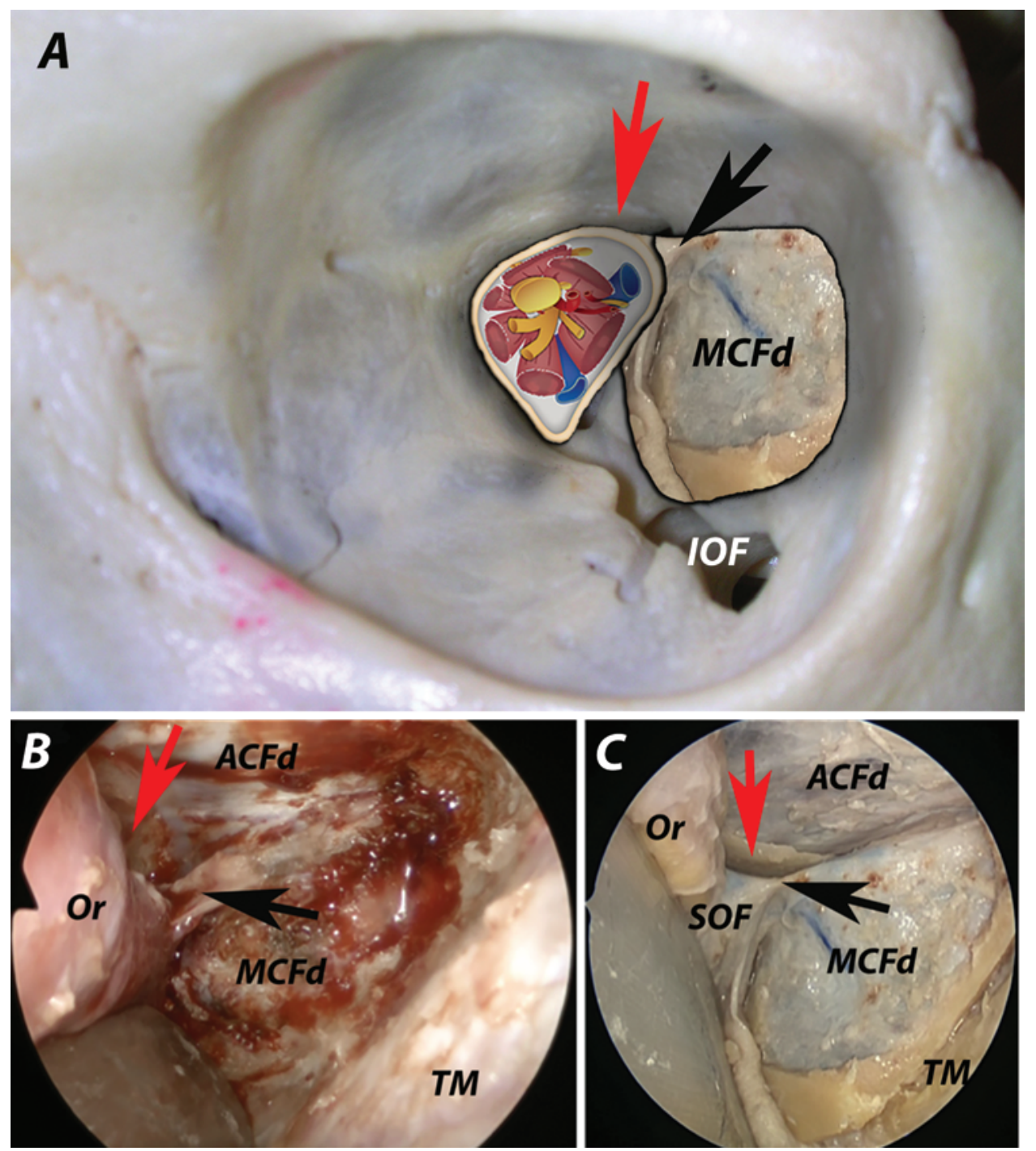

FIG. 2. Photograph of orbit in cadaveric specimen with superimposed artistic drawing showing the position of the left meningoorbital band in a coronal section and photograph from anatomical endoscopic approach (A). Surgical (B) and anatomical (C) visualization of the MOB. The black arrows indicate the MOB; the red arrows indicate the orbit and its contents. ACFd = anterior cranial fossa dura; IOF = inferior orbital fissure; MCFd = middle cranial fossa dura; Or = orbit; SOF = superior orbital fissure; TM = temporalis muscle. Figure is available in color online only.

been developed to treat lesions located in this area, often by means of the endoscopic endonasal routes. . $^{1,4,9,20-22,34}$

Numerous approaches have been proposed, and most of them are based on the philosophy of more extensive bone removal while minimizing cerebral retraction. For example, Yaşargil and colleagues ${ }^{46,47}$ popularized the transsylvian approach to lesions in the sellar and parasellar regions. They used frontotemporal craniotomy with frontoorbital and sphenoidal osteotomy-the so-called "pterional" craniotomy-to take advantage of the cisternal route, while Dolenc ${ }^{15-18}$ pioneered the intra- and extradural approach to the cavernous sinus, which combined a pterional approach with a subtemporal pathway. More recently, Frank and Pasquini ${ }^{21,22}$ proposed a ventral pathway, namely the endoscopic endonasal route, to the cavernous sinus. Their work related primarily to the management of soft lesions (mostly pituitary adenomas).
Each of the proposed approaches has had a significant role in the improvement of surgical treatment of cavernous sinus lesions. Most of these approaches require extensive bone drilling, wide intra- and/or extradural exposure, manipulation of critical neurovascular structures and detachment of temporal muscle to varying degrees. Some of the procedures are also technically demanding and may require a significant expenditure of time and energy.

Considering all these factors, we committed our efforts to evaluating a less-invasive approach to the cavernous sinus, accessing it in a minimally invasive interdural fashion, through what we call an endoscopic superior eyelid transorbital approach.

Cavernous sinus anatomy has been described controversially in a large number of publications. Anatomically speaking, ${ }^{29} 2$ dural layers, medial to the trigeminal foramina and in the lateral cavernous sinus wall, can be 

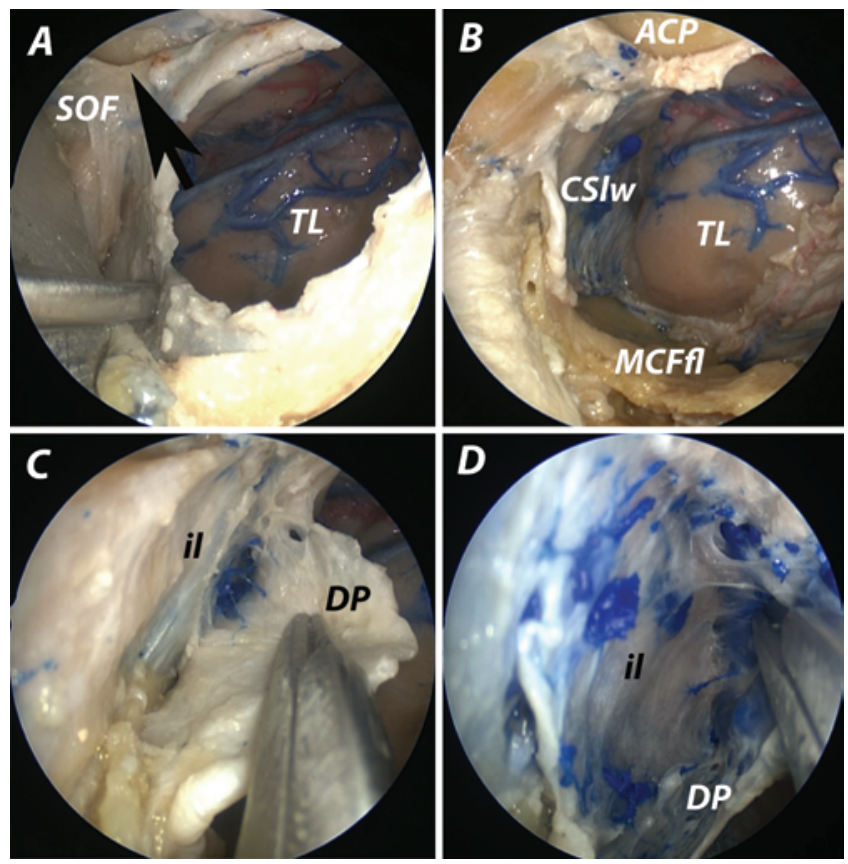

FIG. 3. Endoscopic transorbital exposition of the lateral wall of the cavernous sinus, left orbit. Stepwise dissection (A-D). The black arrow indicates the MOB. ACP = anterior clinoid process; $\mathrm{CSIw}=$ cavernous sinus lateral wall; $\mathrm{DP}=$ deep layer; il = inner layer; $\mathrm{MCFfl}=$ middle cranial fossa floor; SOF = superior orbital fissure; $T L=$ temporal lobe. Figure is available in color online only.

identified. These layers have been demonstrated histologically.

From a surgical standpoint, these layers are of paramount importance because it is possible to separate them, creating the so-called "interdural incision zone." According to Fukuda et al., ${ }^{24}$ the MOB should be considered as a fused periosteal-dural layer that tethers the temporal dura to the periorbita at the level of the lateral aspect of the SOF; its dissection may lead to the interdural space in the lateral wall of the cavernous sinus.

Nonetheless, looking at the specific results of our study and based on our data, we would like to emphasize that an endoscopic superior eyelid approach presents several advantages, which are related to its intrinsic anatomical aspects. Principally, it can be performed very quicklyin our cadaver laboratory it took approximately $30 \mathrm{~min}$ utes-and needs only a small eyelid incision, which is virtually hidden when the patient's eyes are open. Even more importantly, this "anterior" approach reduces to a minimum extradural temporal lobe retraction and cranial nerve manipulation, thus avoiding wide exposure of the cerebrum and the associated complications typically related to these maneuvers. Importantly, the temporalis muscle insertion is left intact, virtually eliminating the risk of atrophy. Last but not least, the interdural ventral "transorbital" corridor, performed on a clear and natural sagittal plane through the MOB, allowed us to expose the entire lateral wall of the cavernous sinus without entering its neurovascular compartment and with a favorable angle of attack. The other available approaches (pterional, frontotemporal and supraorbital), require an interdural dissec-

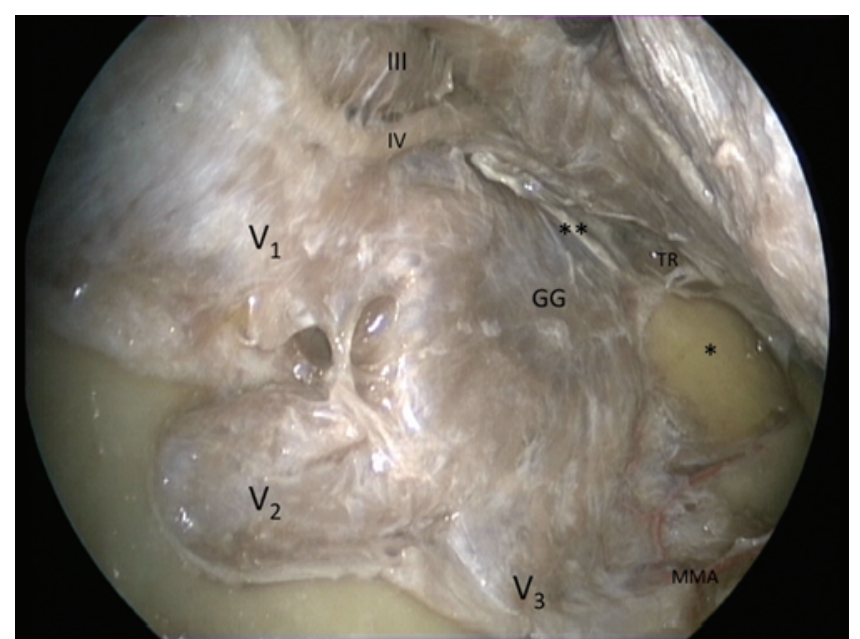

FIG. 4. Complete interdural exposition of the lateral wall of the cavernous sinus via an endoscopic transorbital approach, left orbit. The single asterisk indicates the petrous part of the temporal bone; the double asterisk indicates the dural layer of the Meckel cave. III = oculomotor nerve; IV = trochlear nerve; $\mathrm{GG}$ = gasserian ganglion; $\mathrm{MMA}=$ = middle meningeal artery (entering the foramen spinosum); TR = trigeminal root; $\mathrm{V} 1$ = ophthalmic nerve; $\mathrm{V} 2$ = maxillary branch of the trigeminal nerve; $\mathrm{V} 3=$ mandibular branch of the trigeminal nerve. Figure is available in color online only.

tion performed with a more perpendicular, and thus less favorable, angle of attack. In our view, this could make the dissection, in such a delicate plane, more difficult and consequently risky. In fact, the favorable working direction offered by our anterior transorbital approach allows for quite easy dissection of this interdural plane, completely exposing the lateral wall of the cavernous sinus. By working accurately in this plane, it is possible to inspect the cavernous sinus lateral wall without opening the venous spaces or manipulating any cranial nerves. This route requires minimally invasive drilling of the greater sphenoid wing and offers an immediate exposure of the temporal pole and the lateral wall of the cavernous sinus with a favorable angle of attack (working direction).

The disadvantages of this approach include the unfamiliar perspective of the anatomy of this region as seen from a ventral viewpoint. In consequence, practice in the cadaver laboratory is mandatory to develop familiarity with the approach. We must also stress that in a clinical setting excessive globe retraction or the use of improper equipment for retraction could potentially cause injury to the periorbita or globe. However, despite such potential risks, the clinical application of this procedure in more than 1500 orbital decompressions (made through this approach for Graves' orbitopathy) has demonstrated the feasibility and safety of such a route when properly selected and applied. ${ }^{44}$ Furthermore, ongoing experience in the management of selected spheno-orbital meningiomas seems to confirm the applicability of such an approach in the clinical scenario ${ }^{10}$ (Video 2).

VIDEO 2. Video clip showing surgical application of the endoscopic superior eyelid transorbital approach for a spheno-orbital meningioma. $\mathrm{ACFd}=$ anterior cranial fossa dura; $\mathrm{CSI}$ = cavernous sinus lateral wall; GWS = greater wing of the sphenoid; LWS = lesser wing of the sphenoid; MCF = middle cranial fossa; $\mathrm{MCFd}=$ middle 

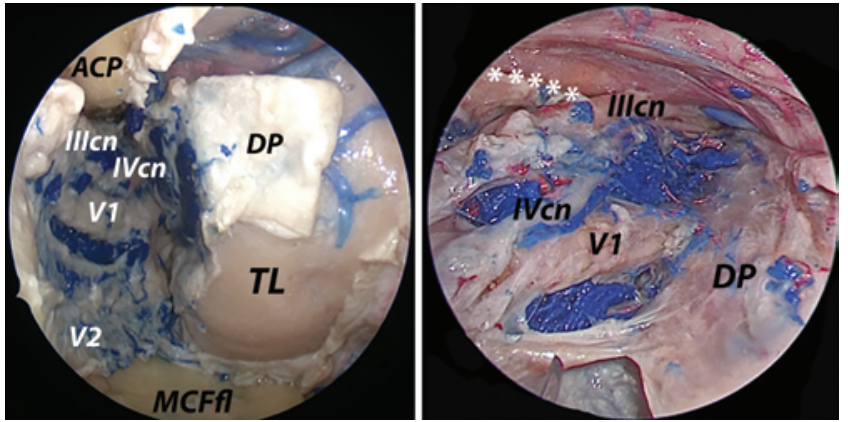

FIG. 5. Close-up views of the lateral wall of the cavernous sinus, accessed via the left orbit. The lateral wall of the cavernous sinus has been disclosed between the temporal lobe and the orbit. The asterisks indicates the inner layer. ACP = anterior clinoid process; $D P=$ dura propria; IIIcn = oculomotor nerve; IVcn = trochlear nerve; V1 = ophthalmic branch of the trigeminal nerve; V2 = maxillary branch of the trigeminal nerve. Figure is available in color online only.

cranial fossa dura; $\mathrm{MOB}=$ meningo-orbital band; $\mathrm{PO}=$ periorbita; $\mathrm{RMA}=$ recurrent meningeal artery; SOF = superior orbital fissure; $\mathrm{TL}=$ temporal lobe; $\mathrm{TM}=$ temporalis muscle. Copyright Alberto $\mathrm{Di}$

Somma. Published with permission. Click here to view.

In such cases, we have partially exposed the lateral wall of the cavernous sinus (at least the anterior part) without the need to retract the temporal lobe. But the practicability of working in this area depends, at least in part, on the space occupied by the tumor. Accordingly, it is important to stress that in a preclinical scenario there is absolutely no need to retract the temporal lobe to expose the lateral wall of the cavernous sinus.

To demonstrate that the approach can be done purely extradurally, we have included an anatomical video highlighting this key technical aspect (see Video 1).

The primary aim of the study, however, is to demonstrate that, by using a transorbital approach, surgeons can enter the interdural space and expose parasellar regions without injuring the neurovascular compartments of the cavernous sinus, other cranial nerves, or the temporal lobes. Selected lesions -i.e., trigeminal schwannomas and meningiomas lateral to the cavernous sinus and covered with the inner layer of the lateral wall of the cavernous sinus - may be the best candidates for this approach. In this context, we should remember that stereotactic radiosurgery is a valid, although palliative, treatment alternative for cavernous sinus pathologies. Nevertheless, we believe that cavernous sinus surgery should still be considered as an important and viable field today.

Finally, regarding the issue of the transorbital route for intracranial pathology, it should be stressed that at present this kind of approach is still in its infancy, so we have to await further developments, in terms of both surgical technique and surgical tools, to reach proper conclusions..$^{10-12}$ Above all, the present work has been designed to provide useful anatomical details with regard to the transorbital approach. A peer understanding of the anatomy represents the backbone of any surgical procedure; we aimed to detail the main features of the MOB as the key landmark in identification of the cavernous sinus.

In this study we have described an interesting surgical approach to this area. Based on our data, we think that
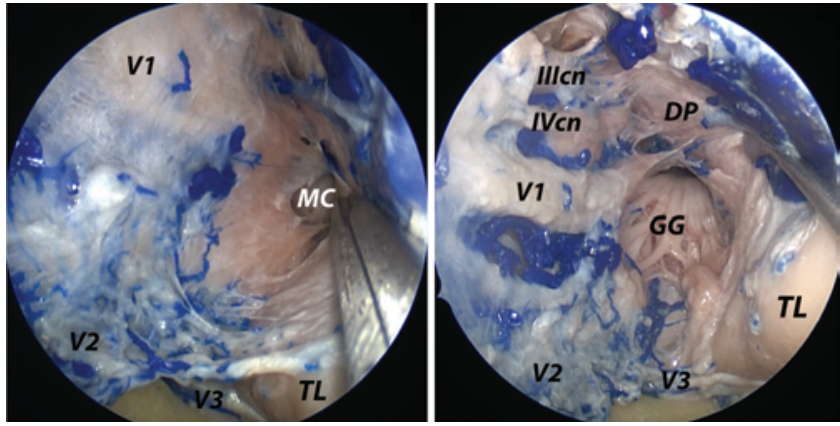

FIG. 6. Close up view of the Meckel cave (MC) and gasserian ganglion (GG), accessed via the left orbit. DP = dura propria; IIIcn = oculomotor nerve (third cranial nerve); IVcn = trochlear nerve (fourth cranial nerve); $\mathrm{TL}=$ temporal lobe; $\mathrm{V} 1=$ ophthalmic branch of the trigeminal nerve; V2 $=$ maxillary branch of the trigeminal nerve; $\mathrm{V} 3=$ mandibular branch of the trigeminal nerve. Figure is available in color online only.

this route may be applicable in the treatment of a variety of lesions, especially tumors, in or around the cavernous sinus. However, at the time of this writing, no clinical case of pure cavernous sinus meningioma had been treated via this approach.

In conclusion, we believe that the transorbital pathway, through a minimally invasive superior eyelid approach and via an interdural corridor, could provide, at least from an anatomical viewpoint, a valid route to access and manage the lateral wall of the cavernous sinus.

\section{Conclusions}

Advances in endoscopic skull base surgery have increased our ability to access complex cranial base regions. The endoscopic transorbital approach provides a simple, rapid and direct view of the cavernous sinus lateral wall. Advantages of this novel interdural pathway include minimal "extradural" brain retraction, no interruption of the temporalis muscle and no entering inside the cavernous sinus neurovascular compartment. This route may be useful for getting inside the lateral wall of the cavernous sinus in a minimally invasive interdural manner. However, it has to be emphasized that surgical series are needed to prove any clinical advantage or disadvantage of this novel route.

\section{Acknowledgments}

This work has been partly supported by the grant "Marató TV3 Project" (411/U/2011, "Quantitative analysis and computer aided simulation of minimally invasive approaches for intracranial vascular lesions").

\section{References}

1. Akutsu H, Kreutzer J, Fahlbusch R, Buchfelder M: Transsphenoidal decompression of the sellar floor for cavernous sinus meningiomas: experience with 21 patients. Neurosurgery 65:54-62, 2009

2. Al-Mefty O: Supraorbital-pterional approach to skull base lesions. Neurosurgery 21:474-477, 1987

3. Al-Mefty O, Anand VK: Zygomatic approach to skull-base lesions. J Neurosurg 73:668-673, 1990

4. Alfieri A, Jho HD: Endoscopic endonasal approaches to the cavernous sinus: surgical approaches. Neurosurgery 49:354-362, 2001 
5. Alfieri A, Jho HD: Endoscopic endonasal cavernous sinus surgery: an anatomic study. Neurosurgery 48:827-837, 2001

6. Alqahtani A, Padoan G, Segnini G, Lepera D, Fortunato S, Dallan I, et al: Transorbital transnasal endoscopic combined approach to the anterior and middle skull base: a laboratory investigation. Acta Otorhinolaryngol Ital 35:173-179, 2015

7. Bly RA, Ramakrishna R, Ferreira M, Moe KS: Lateral transorbital neuroendoscopic approach to the lateral cavernous sinus. J Neurol Surg B Skull Base 75:11-17, 2014

8. Cavallo LM, Cappabianca P, Galzio R, Iaconetta G, de Divitiis E, Tschabitscher M: Endoscopic transnasal approach to the cavernous sinus versus transcranial route: anatomic study. Neurosurgery 56 (2 Suppl):379-389, 2005

9. Cusimano MD, Sekhar LN, Sen CN, Pomonis S, Wright DC, Biglan AW, et al: The results of surgery for benign tumors of the cavernous sinus. Neurosurgery 37:1-10, 1995

10. Dallan I, Castelnuovo P, Locatelli D, Turri-Zanoni M, AlQahtani A, Battaglia P, et al: Multiportal combined transorbital transnasal endoscopic approach for the management of selected skull base lesions: preliminary experience. World Neurosurg 84:97-107, 2015

11. Dallan I, Castelnuovo P, Turri-Zanoni M, Fiacchini G, Locatelli D, Battaglia P, et al: Transorbital endoscopic assisted management of intraorbital lesions: lessons learned from our first 9 cases. Rhinology 54:247-253, 2016

12. Dallan I, Locatelli D, Turri-Zanoni M, Battaglia P, Lepera D, Galante N, et al: Transorbital endoscopic assisted resection of a superior orbital fissure cavernous haemangioma: a technical case report. Eur Arch Otorhinolaryngol 272:3851-3856, 2015

13. de Divitiis E, Cappabianca P, Cavallo LM: Endoscopic transsphenoidal approach: adaptability of the procedure to different sellar lesions. Neurosurgery 51:699-707, 2002

14. Doglietto F, Lauretti L, Frank G, Pasquini E, Fernandez E, Tschabitscher M, et al: Microscopic and endoscopic extracranial approaches to the cavernous sinus: anatomic study. Neurosurgery 64 (5 Suppl 2):413-422, 2009

15. Dolenc V: Direct microsurgical repair of intracavernous vascular lesions. J Neurosurg 58:824-831, 1983

16. Dolenc VV: A combined epi- and subdural direct approach to carotid-ophthalmic artery aneurysms. J Neurosurg 62:667672,1985

17. Dolenc VV: Frontotemporal epidural approach to trigeminal neurinomas. Acta Neurochir (Wien) 130:55-65, 1994

18. Dolenc VV: Transcranial epidural approach to pituitary tumors extending beyond the sella. Neurosurgery 41:542-552, 1997

19. Erturk M, Kayalioglu G, Govsa F, Varol T, Ozgur T: The cranio-orbital foramen, the groove on the lateral wall of the human orbit, and the orbital branch of the middle meningeal artery. Clin Anat 18:10-14, 2005

20. Ferreli F, Turri-Zanoni M, Canevari FR, Battaglia P, Bignami $\mathrm{M}$, Castelnuovo P, et al: Endoscopic endonasal management of non-functioning pituitary adenomas with cavernous sinus invasion: a 10-year experience. Rhinology 53:308-316, 2015

21. Frank G, Pasquini E: Endoscopic endonasal approaches to the cavernous sinus: surgical approaches. Neurosurgery 50:675, 2002 (Letter)

22. Frank G, Pasquini E: Endoscopic endonasal cavernous sinus surgery, with special reference to pituitary adenomas. Front Horm Res 34:64-82, 2006

23. Froelich SC, Aziz KM, Levine NB, Theodosopoulos PV, van Loveren HR, Keller JT: Refinement of the extradural anterior clinoidectomy: surgical anatomy of the orbitotemporal periosteal fold. Neurosurgery 61 (5 Suppl 2):179-186, 2007

24. Fukuda H, Evins AI, Burrell JC, Iwasaki K, Stieg PE, Bernardo A: The meningo-orbital band: microsurgical anatomy and surgical detachment of the membranous structures through a frontotemporal craniotomy with removal of the an- terior clinoid process. J Neurol Surg B Skull Base 75:125132,2014

25. Hakuba A: [Surgical approaches to the cavernous sinus-repair of a C-C fistula at the $\mathrm{C} 5$ portion of the internal carotid artery.] No Shinkei Geka 14:601-607, 1986 (Jpn)

26. Hakuba A, Nishimura S, Shirakata S, Tsukamoto M: [Surgical approaches to the cavernous sinus. Report of 19 cases (author's transl).] Neurol Med Chir (Tokyo) 22:295-308, 1982 (Jpn)

27. Hakuba A, Tanaka K, Suzuki T, Nishimura S: A combined orbitozygomatic infratemporal epidural and subdural approach for lesions involving the entire cavernous sinus. J Neurosurg 71:699-704, 1989

28. Iwai Y, Hakuba A, Katsuyama J, Egashira M, Kitano S, Nagata $\mathrm{Y}$, et al: [Inflammatory granulomas extending from the sphenoid sinus to the cavernous sinus: report of three cases.] No Shinkei Geka 19:465-470, 1991 (Jpn)

29. Kinzel A, Spangenberg P, Lutz S, Lücke S, Harders A, Scholz $\mathrm{M}$, et al: Microsurgical and histological identification and definition of an interdural incision zone in the dorsolateral cavernous sinus. Acta Neurochir (Wien) 157:1359-1367, 2015

30. Knosp E, Perneczky A, Koos WT, Fries G, Matula C: Meningiomas of the space of the cavernous sinus. Neurosurgery 38:434-444, 1996

31. Koppe M, Gleizal A, Orset E, Bachelet JT, Jouanneau E, Rougeot A: Superior eyelid crease approach for transobital neuroendoscopic surgery of the anterior cranial fossa. J Craniofac Surg 24:1616-1621, 2013

32. Lim JH, Sardesai MG, Ferreira M Jr, Moe KS: Transorbital neuroendoscopic management of sinogenic complications involving the frontal sinus, orbit, and anterior cranial fossa. J Neurol Surg B Skull Base 73:394-400, 2012

33. Moe KS, Bergeron CM, Ellenbogen RG: Transorbital neuroendoscopic surgery. Neurosurgery 67 (3 Suppl Operative):ons16-ons28, 2010

34. Newman S: A prospective study of cavernous sinus surgery for meningiomas and resultant common ophthalmic complications (an American Ophthalmological Society thesis). Trans Am Ophthalmol Soc 105:392-447, 2007

35. Nishio A, Nishijima Y, Tsuruno T, Murata T, Hakuba A: Direct carotid-cavernous sinus fistula due to ruptured intracavernous aneurysm treated with electrodetachable coils-case report. Neurol Med Chir (Tokyo) 39:681-684, 1999

36. Ohata K, El-Naggar A, Takami T, Morino M, El-Adawy Y, El-Sheik K, et al: Efficacy of induced hypotension in the surgical treatment of large cavernous sinus cavernomas. J Neurosurg 90:702-708, 1999

37. O'Sullivan MG, van Loveren HR, Tew JM Jr: The surgical resectability of meningiomas of the cavernous sinus. Neurosurgery 40:238-247, 1997

38. Parkinson D: Carotid cavernous fistula: direct repair with preservation of the carotid artery. Technical note. J Neurosurg 38:99-106, 1973

39. Parkinson D: Direct obliteration of carotid-cavernous fistulas. J Neurosurg 66:948, 1987

40. Parkinson D: A surgical approach to the cavernous portion of the carotid artery. Anatomical studies and case report. J Neurosurg 23:474-483, 1965

41. Parkinson D: Transcavernous repair of carotid cavernous fistula. Case report. J Neurosurg 26:420-424, 1967

42. Perneczky A, Knosp E, Matula C: Cavernous sinus surgery. Approach through the lateral wall. Acta Neurochir (Wien) 92:76-82, 1988

43. Sekhar LN, Sen CN, Jho HD, Janecka IP: Surgical treatment of intracavernous neoplasms: a four-year experience. Neurosurgery 24:18-30, 1989

44. Sellari-Franceschini S, Berrettini S, Santoro A, Nardi M, Mazzeo S, Bartalena L, et al: Orbital decompression in 
graves' ophthalmopathy by medial and lateral wall removal. Otolaryngol Head Neck Surg 133:185-189, 2005

45. Umansky F, Nathan H: The lateral wall of the cavernous sinus. With special reference to the nerves related to it. J Neurosurg 56:228-234, 1982

46. Yaşargil MG, Antic J, Laciga R, Jain KK, Hodosh RM, Smith RD: Microsurgical pterional approach to aneurysms of the basilar bifurcation. Surg Neurol 6:83-91, 1976

47. Yaşargil MG, Reichman MV, Kubik S: Preservation of the frontotemporal branch of the facial nerve using the interfascial temporalis flap for pterional craniotomy. Technical article. J Neurosurg 67:463-466, 1987

\section{Disclosures}

The authors report no conflict of interest concerning the materials or methods used in this study or the findings specified in this paper.

\section{Author Contributions}

Conception and design: Di Somma, Dallan, Turri-Zanoni, de Notaris. Acquisition of data: Di Somma, Dallan, Turri-Zanoni. Analysis and interpretation of data: Di Somma, Dallan, TurriZanoni, Fiacchini. Drafting the article: Di Somma, Dallan, TurriZanoni, Fiacchini, de Notaris. Critically revising the article: Dallan, Prats-Galino, Solari, de Notaris. Reviewed submitted version of manuscript: Dallan, Prats-Galino, Solari, Alobid, Castelnuovo, Catapano, de Notaris. Statistical analysis: de Notaris. Study supervision: Dallan, Prats-Galino, Castelnuovo, Catapano, de Notaris.

\section{Supplemental Information}

Videos

Video 1. https://vimeo.com/181195690.

Video 2. https://vimeo.com/181195874.

\section{Correspondence}

Alberto Di Somma, Via Sergio Pansini, 5, Naples 80131, Italy. email: albertodisomma87@gmail.com. 